\title{
COLÉGIO INVISÍVEL, REVISÃO PELOS PARES E NORMALIZAÇÃO DOCUMENTÁRIA NA REVISTA DO INSTITUTO HISTÓRICO E GEGRÁFICO DE SÃO PAULO
}

\author{
COLEGIO INVISIBLE, REVISIÓN POR LOS PARES Y \\ NORMALIZACIÓN EN LA REVISTA DO INSTITUTO \\ HISTÓRICO E GEOGRÁFICO DE SÃO PAULO
}

\author{
Carlos Roberto Massao Hayashi* \\ Camila Carneiro Dias Rigolin** \\ Vera Aparecida Lui Guimarães *** \\ Maria Cristina Piumbato Innocentini Hayashi****
}

\begin{abstract}
RESUMO
Introdução: $O$ artigo aborda a revisão pelos pares, o funcionamento do colégio invisível, o processo editorial (impressão, tiragem, periodicidade, distribuição) e a normalização documentária de um periódico que possui 121 anos de existência: a Revista do Instituto Histórico e Geográfico de São Paulo (RIHGSP).

Objetivo: Analisar aspectos da comunicação científica, da editoração e da normalização documentária da RIHGSP.

Metodologia: Ancorado na perspectiva teórica da Ciência da Informação e da Sociologia da Ciência, o corpus analisado foi composto por 33 artigos publicados na RIHGSP entre 1895 e 2004.

Resultados: $O$ estudo permite compreender como os editores e autores - que faziam parte da intelectualidade paulista e brasileira - e publicavam seus artigos na RIHGSP integravam parte de um colégio invisível no campo dos estudos históricos.

Conclusões: Os resultados obtidos podem iluminar futuros estudos sobre periódicos congêneres em busca de semelhanças ou diferenças com relação a esses aspectos.

Palavras-chave: Revista do Instituto Histórico e Geográfico de São Paulo.Colégio invisível. Revisão pelos pares. Comunicação científica.

*Doutor em Educação pela Universidade Federal de São Carlos (UFSCar). Docente do Programa de Pós-Graduação em Ciência, Tecnologia e Sociedade da UFSCar (PPGCTS/UFSCar). E-mail: massao@ufscar.br

** Doutora em Política Científica e Tecnológica pela Universidade Estadual de Campinas (UNICAMP). Docente da Universidade Federal de São Carlos (UFSCar). E-mail: diasrigolin@ufscar.br

***Doutora em Ciência, Tecnologia e Sociedade pela Universidade Federal de São Carlos
\end{abstract}

Inf. Inf., Inf., Londrina, v. 21, n. 3, p. 5 - 33, set./dez., 2016.

http:www.uel.br/revistas/informacao/ 
Carlos Roberto Massao Hayashi, Camila Carneiro Dias Rigolin, Vera Aparecida Lui Guimarães, Maria Cristina Piumbato Innocentini Hayashi

Colégio invisível, revisão pelos pares e normalização documentária na revista do instituto histórico e geográfico de São Paulo

(UFSCar). Bibliotecário da Universidade Federal de São Carlos (UFSCar). E-mail: veralui@ufscar.br

****Doutora em Educação pela Universidade Federal de São Carlos (UFSCar). Docente do Programa de Pós-Graduação em Ciência, Tecnologia e Sociedade da UFSCar (PPGCTS/UFSCar). E-mail: dmch@ufscar.br

\section{INTRODUÇÃO}

No prólogo do estudo que realizou sobre a epopeia bandeirante, e que caracteriza o universo letrado paulista em seus vínculos sociais e institucionais, bem como suas correlações políticas, Ferreira (2002) reclamava da escassez de estudos sobre a historiografia e a literatura em São Paulo produzida pelo Instituto Histórico e Geográfico de São Paulo (IHGSP), em períodos anteriores a 1930. Na visão do autor a "agremiação paulista não foi objeto de exame específico" com o mesmo estatuto dado ao Instituto Histórico e Geográfico Brasileiro (IHGB) no estudo clássico de Manoel Salgado Guimarães (1988), aos quais acrescentaríamos os de Schwarcz (1993), Lucia Maria Paschoal Guimarães $(1995,2007)$ e Arno Wehling $(2009,2010)$.Essa visão corrobora os achados da pesquisa bibliométrica desenvolvida por Pereira, Ferreira Junior e Hayashi (2013) ao mostrarem que olHGB tem sido objeto de estudo de inúmeras teses e dissertações no Brasil, mas são poucos os estudos sobre o IHGSP e, principalmente sobre sua revista.

Essas foram as motivações para a realização de um estudo sobre a revista do IHGSP - doravante denominada RIHGSP -que em 2015 completou 121 anos de existência - visando traçar o perfil desse periódico, e oferecer subsídios para compreensão de sua relevante contribuição no cenário historiográfico brasileiro. Desse modo, este artigo tem como objetivo analisar aspectos da comunicação científica e da normalização documentária da RIHGSP. A perspectiva teórica adotada é a da Comunicação Científica, área transversal de intersecção com a Sociologia da Ciência e a Ciência da Informação, que permitiu estabelecer categorias de análise que privilegiaram

Inf. Inf., Londrina, v. 21, n. 3, p. 5 - 33, set./dez., 2016. 
Carlos Roberto Massao Hayashi, Camila Carneiro Dias Rigolin, Vera Aparecida Lui Guimarães, Maria Cristina Piumbato Innocentini Hayashi

Colégio invisível, revisão pelos pares e normalização documentária na revista do instituto histórico e geográfico de São Paulo

interpretar o funcionamento do colégio invisível formado pelos membros do IHGSP e seus colaboradores, o processo de revisão pelos pares na avaliação dos artigos publicados, o processo editorial da revista em relação a sua impressão, tiragem, periodicidade e distribuição; e finalmente, os aspectos formais da RIHGSP tais como a normalização documentária - isto é, a ficha catalográfica, a legenda bibliográfica, as instruções aos autores -, entre outros.

O corpus de análise foi composto por 33 artigos selecionados por meio da expressão de busca "revista" dentre aqueles que integram a coleção de 96 volumes publicados desde 1895 até 2004, e consolidados em um CD-ROM comercializado pelo IHGSP. A distribuição dos 33 artigos nesse período foi a seguinte: 1895 (3), 1896 (1), 1912 (1), 1933-1934 (1), 1937-1939 (11), 19641967 (4), 1985 (1), 1989 (1). 1992 (1), 1994-1997 (5), 1999 (1) e 2004 (2). Em seguida, foi realizada análise de conteúdo dos artigos selecionados, que foram lidos integralmente, para estabelecimento das categorias de análise.

Além dessa introdução - que apresenta o tema, o objetivo e a metodologia da pesquisa - e das conclusões finais, o artigo está estruturado em seis partes. Na seção seguinteé apresentado um perfil do Instituto Histórico e Geográfico de São Paulo (IHGSP) que fornece o contexto histórico que propiciou o surgimento da RIHGSP, cujo primeiro volume foi publicado apenas um ano após a fundação do Instituto. As demais seções enfocamos processo de revisão pelos pares e o colégio invisível, o processo editorial e os aspectos formais da RIHGSP. Finalmente são apresentadas as considerações finais, as referências e a lista com os autores e títulos dos 33 artigos publicados na RIHGSPe analisados nesse artigo.

\section{ESBOÇO HISTÓRICO DO INSTITUTO HISTÓRICO E GEOGRÁFICO DE SÃO PAULO (IHGSP)}

Durante muito tempo, o Instituto Histórico e Geográfico Brasileiro (IGHB), fundado em 21 de outubro de 1838, representou o único expoente da produção do saber histórico nacional. Situado no Rio de Janeiro, a sede da

Inf. Inf., Londrina, v. 21, n. 3, p. 5 - 33, set./dez., 2016.

http:www.uel.br/revistas/informacao/ 
Carlos Roberto Massao Hayashi, Camila Carneiro Dias Rigolin, Vera Aparecida Lui Guimarães, Maria Cristina Piumbato Innocentini Hayashi

Colégio invisível, revisão pelos pares e normalização documentária na revista do instituto histórico e geográfico de São Paulo

corte, o que Ihe possibilitava créditos suficientes para representar toda a nação, reuniu a nata da sociedade e da intelectualidade da época, juntamente com os sócios efetivos e correspondentes, que eram, por sua vez, provenientes de outras partes do país e do mundo. Como refere Callari (2001), a hegemonia do IHGBsó seria parcialmente quebrada quando em 1862 foi criado o Instituto Arqueológico e Geográfico Pernambucano (IAGP). A partir de então, outros Institutos de base local, procuravam se filiar ao modelo proposto pelo IHGB, ao mesmo tempo em que buscavam realçar aspectos da história local, salientando a importância da região na composição da história nacional.

Nesse contexto,conforme esclarece o site do IHGSP, em $1^{\circ}$. de novembro de 1894 foi fundado o IHGSP, e seus princípios norteadores prevalecem até hoje: promover o estudo e o desenvolvimento da História e Geografia do Brasil e principalmente do Estado de São Paulo e, bem assim, ocupar-se de questões e assuntos literários, científicos, artísticos e industriais, que possam interessar ao país sob qualquer ponto-de-vista; publicar uma revista, uma vez ao menos anualmente, dando conta da vida da associação e onde fiquem arquivados os trabalhos que o Instituto julgar úteis e interessantes; manter correspondência e relações com as sociedades congêneres, nacionais e estrangeiras.

Desde a sua criação, esta centenária instituição vem assumindo papel relevante na construção da identidade cultural paulista. Esse protagonismo é resultante da presença, entre os seus membros, de renomados intelectuais, autores de obras significativas da bibliografia nacional, bem figuras do mundo político brasileiro. De sua fundação, até a presente data, exerceram a presidência do IHGSP destacados representantes da elite intelectual e política brasileira, entre eles Cesário Mota Júnior, Manuel Antonio Duarte de Azevedo; Luiz de Toledo Piza e Almeida, Altino Arantes, Afonso Antônio de Freitas, José Torres de Oliveira, Ernesto de Sousa Campos, José Leite Pedro Cordeiro, Aureliano Leite, Ernesto de Moraes Leme,Lycurgo de Castro Santos Filho,Hernâni Donato, Roberto Machado Carvalho e Nelly Martins Ferreira Candeias.

Inf. Inf., Londrina, v. 21, n. 3, p. 5 - 33, set./dez., 2016. 
Carlos Roberto Massao Hayashi, Camila Carneiro Dias Rigolin, Vera Aparecida Lui Guimarães, Maria Cristina Piumbato Innocentini Hayashi

Colégio invisível, revisão pelos pares e normalização documentária na revista do instituto histórico e geográfico de São Paulo

Na primeira metade do século XX, o IHGSP registrou a participação de estudiosos do porte de Affonso Taunay, Clovis Bevilacqua, Euclides da Cunha, Fernando de Azevedo, Alcântara Machado, Julio de Mesquita Filho, Mário de Andrade, Orígenes Lessa, Roberto Simonsen e Sérgio Milliet. Entre seus presidentes honorários figuram Prudente José de Moraes Barros, José Maria da Silva Paranhos (o Barão do Rio Branco), Rui Barbosa, Afonso d'Escragnolle Taunay, Washington Luís, Rodrigues Alves, Fernando Prestes, Ernesto de Moraes Leme, Julio Prestes, Lycurgo de Castro Santos Filho e Hernâni Donato. Dentre os sócios mais destacados, no panorama brasileiro do final do século XX, incluem-se Alice Canabrava, Anita Novinsky, Aziz Ab'Saber, Erwin Theodor Rosenthal, Miguel Reale, Paulo Bonfim, Samuel Pfromm Neto, Paulo Nogueira Neto, José Marques de Melo, Ruy Althenfelder Silva e Vavy Pacheco Borges. O perfil e a pluralidade desses nomes fazia com que o IHGSP mantivesse "um aspecto fortemente elitizado, com representantes destacados da vida política, econômica, cultural e social do país", na visão de Ferreira e Mahl (2011, p.9).Do ponto de vista profissional predominou no IHGSP sócios com formação nas áreas do Direito, Medicina e Engenharias, além de um rol de bacharéis formados em cursos diversos, como farmácia, belas artes e humanidades, conforme acentuado por Ferreira (2002, p. 103).

O IHGSP não era e nem tinha o objetivo de se apresentar como uma associação de caráter popular, dado que, quando se analisa o perfil socioeconômico de seus sócios, verifica-se que "a agremiação não se colocava como um representante da multiplicidade de grupos sociais que se formavam naquela fremente São Paulo, que crescia de forma vertiginosa no início do século XX", conforme argumentam Ferreira e Mahl (2011, p. 10). Na visão desses autores, o IHGSP era um espaço genuinamente paulista e representava, de forma preponderante "os valores daqueles que se consideravam descendentes, física e/ou moralmente, dos primeiros troncos paulistas".

Inf. Inf., Londrina, v. 21, n. 3, p. 5 - 33, set./dez., 2016. 
Carlos Roberto Massao Hayashi, Camila Carneiro Dias Rigolin, Vera Aparecida Lui Guimarães, Maria Cristina Piumbato Innocentini Hayashi

Colégio invisível, revisão pelos pares e normalização documentária na revista do instituto histórico e geográfico de São Paulo

Assim, o IHGSP se posicionava como um local privilegiado de convívio para os membros das classes dirigentes tanto em nível estadual quanto federal; e foi a partir dessa posição muito bem delimitada e constantemente reavivada nas páginas das revistas, por meio dos estudos genealógicos e das biografias efusivas, que se construiu um conjunto de afirmações e crenças sobre o patrimônio paulista (FERREIRA; MAHL, 2011, p. 10).

Nas palavras de Scabin (2011, p. 1), as atividades do recém-fundado IHGSP representavam "a tentativa de construção de uma História do Brasil por um viés paulista, justificando com um passado glorioso e altivo a crescente influência da elite cafeeira no cenário nacional".

Referindo-se aos primeiros decênios de atividade acadêmica do Instituto, Ferreira (1995, p. 15) assinalou que outra característica reveladora do ambiente intelectual que prevalecia no Instituto dizia respeito "à composição inteiramente masculina da entidade, de acordo com os costumes e mentalidades vigentes", ou seja, "somente na passagem do século seriam admitidas algumas mulheres, provenientes, é claro, de famílias de estirpe".

Nesse aspecto, é válido assinalar que a primeira mulheradmitida como sócia efetiva ${ }^{1}$ do IHGSP foi Maria Rennotte ${ }^{2}$ (1852-1942), indicada por Orville Derby, Eduardo Prado e Denamerico Rangel na sessão realizada no dia 4 de maio de 1901 (IHGSP, 1900-1901, p.608).Posteriormente, até 1912, outras mulheres são admitidas como sócias honorárias do IHGSP, entre elasa escritora e historiadora Mary Robinson Wright (1901), a aristocrata, proprietária de terras e feminista Veridiana Valéria da Silva Prado (1902). E como sócias

\footnotetext{
1 De acordo com os estatutos do IHGSP, sócios ingressantes em uma categoria poderiam ser transferidos para outras, geralmente para as de "honorários" ou "beneméritos", na maioria das vezes pelas contribuições e relevantes serviços prestados ao Instituto.

2 Nascida na Bélgica chegou ao Brasil em 1878, e em 1881 foi contratada para dar aulas no Colégio Piracicabano (Piracicaba-SP), instituição de ensino fundada por metodistas do sul dos EUA. Além de professora foi médica ilustre, diplomando-se em 1892 pelo Women's Medical CollegeofPensylvania (Filadélfia-EUA), e teve o seu título validado no Brasil em 1895 com a apresentação da tese "Influência da educação da mulher sobre a medicina social" à Faculdade de Medicina do Rio de Janeiro. Aliás, essa tese foi apresentada em sessão do IHGSP em 8 de abril de 1901.
}

Inf. Inf., Londrina, v. 21, n. 3, p. 5 - 33, set./dez., 2016. 
Carlos Roberto Massao Hayashi, Camila Carneiro Dias Rigolin, Vera Aparecida Lui Guimarães, Maria Cristina Piumbato Innocentini Hayashi

Colégio invisível, revisão pelos pares e normalização documentária na revista do instituto histórico e geográfico de São Paulo

correspondentes ${ }^{3}$, a escritora Júlia Lopes de Almeida, (1902), a poeta Ibrantina Cardona (1905), a Viscondessa de Cavalcanti(1905); Lydia de Souza Rezende (1910);Olga de Moraes Sarmento (1910) e a poeta Delminda da Silveira de Souza (1912).A médica e política Carlota Pereira de Queiróz, fundadora da Academia Brasileira de Mulheres Médicas (1942) e deputada eleita à Assembleia Nacional Constituinte (1933) também fez parte dos quadros do IHGSP sendo admitida como sócia honorária em 1940.

Mais recentemente, asessão de 30 de outubro de 1996 do Instituto (IHGSP, 1999, p 226, 234) aprovou a admissão da profa. Nelly Martins Ferreira Candeias como sócia titular do IHGSP. Na Diretoria do triênio 1999 a 2002 ela foi eleita para o cargo de $1^{\circ}$. Secretária, e compôs a Comissão de Redação da RIHGSP. Nas eleições para os triênios 2002-2004, de 2005-2007 foi eleita para a presidência do IHGSP (IHGSP, 2004b, p. 4), cargo que ocupa até o momento, já que de acordo com a relação de presidentes informada no site do Instituto seu mandato se encerrará em 2015 (IHGSP, 2015). Como o último volume da RIHGSP corresponde ao ano de 2004, não foi possível obter informações sobre eleições posteriores ao triênio 2005-2007. AAta de Assembleia Geral, de 13/10/2004 (IHGSP, 2004a, p. 159) informa a reeleição de Nelly Candeias para o triênio 2005-2008,mas a relação de membros da Diretoria do site do IHGSP informa que a gestão atual é de 2002-2015 (IHGSP, 2015). Desde a fundação, as eleições para a Diretoria do IHGSP são realizadas em outubro e a posse ocorre em janeiro do ano seguinte, o que permite inferir que o seu mandato terminará em outubro de 2014 e a posse da nova Diretoria ocorrerá em janeiro de 2015.

\footnotetext{
3 Sócios correspondentes eram aqueles que residiam fora da cidade de São Paulo, em outras
} localidades do estado e do país, e até mesmo no exterior.

Inf. Inf., Londrina, v. 21, n. 3, p. 5 - 33, set./dez., 2016. 
Carlos Roberto Massao Hayashi, Camila Carneiro Dias Rigolin, Vera Aparecida Lui Guimarães, Maria Cristina Piumbato Innocentini Hayashi

Colégio invisível, revisão pelos pares e normalização documentária na revista do instituto histórico e geográfico de São Paulo

\section{A REVISÃO PELOS PARES E O COLÉGIO INVISÍVEL NA RIHGSP}

Em 1895, um ano após a fundação do Instituto Histórico e Geográfico de São Paulo (IHGSP), a RIHGSPvem à luz com a publicação do primeiro volume composto por dois fascículos publicados respectivamente em $1895 \mathrm{e}$ 1896.Ferreira (2002, p. 114) comenta que:

[...] foi à revista, publicada anualmente, que os sócios destinaram a maior parte de seu labor. Ela daria visibilidade ao IHGSP, circulando entre um público leitor limitado, porém qualitativamente escolhido: homens eruditos e de letras em geral, políticos e burocratas em variados níveis, famílias abastadas e de posses medianas. Em 1904, os diretores da agremiação enviaram alguns dos seus exemplares à Exposição Internacional de São Luiz, realizada nos Estados Unidos. Reconhecida e premiada, exatamente no país em que os paulistas buscavam se espelhar, ela recebeu uma medalha de ouro e um diploma, guardados como motivo de orgulho do Instituto e do culto às tradições gloriosas de São Paulo.

Ao mesmo tempo em que a página de abertura da RIHGSP dirigida "Ao Leitor" exaltava os propósitos do Instituto na busca por interpretar edar a conhecer o passado histórico da "civilização paulista", o texto também dava como certa a procura da Revista para "leitura daqueles que desejam conhecer o modo sério e consciencioso pelo qual o Instituto vai se desempenhando dos seus patrióticos intuitos. Aos leitores compete julgar se nos desempenhamos dignamente do encargo" (IHGSP, 1895a, p.II).

Em relação ao conteúdo, por força dos Estatutos do Instituto, a RIHGSP deveria publicar "além das atas das sessões e assembleias, o relatório anual da Diretoria e todos os trabalhos e documentos que forem apresentados pelos sócios, discutidos e aprovados", bem como "a relação nominal dos sócios, suas categorias e épocas de admissão, o catálogo ou relação dos donativos, ofertas, doações ou legados recebidos durante o ano social, comindicação de nomes dos doadores ou ofertantes" (IHGSP, 1938a, p. 267).

Inf. Inf., Londrina, v. 21, n. 3, p. 5 - 33, set./dez., 2016. 
Carlos Roberto Massao Hayashi, Camila Carneiro Dias Rigolin, Vera Aparecida Lui Guimarães, Maria Cristina Piumbato Innocentini Hayashi

Colégio invisível, revisão pelos pares e normalização documentária na revista do instituto histórico e geográfico de São Paulo

Ou seja, a RIHGSP cumpria uma dupla função: administrativa, ao publicar documentos internos com a finalidade de prestação de contas das ações fiscais da Diretoria do Instituto, e de disseminação da cultura histórica e literária principalmente paulista, por meio de artigos marcados "pelo beletrismo próprio da intelectualidade do período", cujos autores expressavam em seus textos "uma mistura singular de erudição e rebuscamento estilístico, à luz do que entendiam por ciência, transitando entre diferentes gêneros narrativos e temáticos", conforme assinalaram Ferreira e Mahl (2011, p. 8-9).

Assim, geralmente compunham a primeira parte da RIHGSP artigos elaborados pelos sócios, ou então "encomendados" pela Diretoria do Instituto a pretexto da comemoração de eventos históricos, tais como o IV Centenário do Descobrimento do Brasil (1900), o $1^{\circ}$ centenário da Independência (1922), o IV Centenário (1954) e os 450 anos de São Paulo (2004), bem como os aniversários do IHGSP, e de cidades como Santos, São Vicente, Mogi Mirim, Itu, por exemplo.

Também eram publicados nessa parte os discursos de posse e de recepção de sócios e nobiliarquias, ou seja, genealogias de famílias paulistas entre elas dois de volumes de uma obra de três, da Nobiliarquia Paulistana de autoria de Pedro Taques de Almeida Paes Leme, e que foram publicados nos volumes 39 (1940) e 39-Bis (1944), uma vez que o conteúdo do primeiro volume integrou a coleção da Revista do IHGB (volumes 32 a 35) publicados entre 1869 a 1872 .

Na visão de Ferreira (2002, p. 128), essas genealogias e biografias construíam "trajetórias incomuns, responsáveis pelas grandes realizações, individuais ou clânicas, fazendo-as transcender os marcos da própria colonização, com base no recuo a um passado longínquo europeu" de tal forma que a nobilitação das personagens revelava "a ambição de fixar uma epopeia paulista, sustentada por indivíduos aos quais se atribuía uma força superior".

Também havia na primeira parte da RIHGSP um conjunto de artigos com esboços biográficos de sócios (Afonso d'Escragnole Taunay, Theodoro Sampaio) e de personagens históricos e literários (Diogo Feijó, Santos Dumont, 
Carlos Roberto Massao Hayashi, Camila Carneiro Dias Rigolin, Vera Aparecida Lui Guimarães, Maria Cristina Piumbato Innocentini Hayashi

Colégio invisível, revisão pelos pares e normalização documentária na revista do instituto histórico e geográfico de São Paulo

Rui Barbosa, Castro Alves, Paulo Eiró, Paulo Setúbal, etc.). Nessas narrativas biográficas, seguiam a fórmula "vida-obra, privado-público e físico psicológico", e conforme explica Ferreira (2002, p. 127) lembravam:

[...] a infância e as dificuldades enfrentadas pelo personagem, as atitudes arrojadas, a incompreensão, muitas vezes, dos que o cercavam e, afinal, o sucesso, atingido na fase madura da vida, ou somente póstumo. Para arrancar das cinzas as figuras do passado, os autores procuravam recriar o clima da época em que elas viveram, restituindo-lhes a vida, por exemplo, com os recursos dos textos em prosa. Não é extraordinário, dessa maneira, surgirem diálogos imaginários entre as personagens enfocadas, em meio ao relato objetivo e convencional da história.

A segunda parte da RIHGSP trazia relatórios da Diretoria composto por balanços das receitas e despesas; pareceres da Comissão de Contas; atas das sessões realizadas no IHGSP; relação dos membros do Instituto, e de livros, jornais, revistas, mapas, além de retratos, gravuras, selos, fotografias, medalhas, moedas, entre outros materiais oferecidos pelos sócios à Biblioteca e ao Arquivo do Instituto.

Os necrológios de sócios e de figuras de destaque da história paulista e brasileira eram incluídos nessa parte final da Revista.Aliás, sobre os necrológios é válido registrar que o§ $2^{\circ}$. do artigo 24, no Estatuto de 1901 e o art. $26^{\circ}$. do Estatuto de 1938, atribuíam ao orador oficial do Instituto o papel de "fazer na sessão magna de $1^{\circ}$. de novembro, o elogio histórico dos sócios falecidos no ano social" (Cf. IHGSP, 1938a, p.266, 1939c, p. 444). Conforme as palavras de José Torres de Oliveira, na sessão magna de $1^{\circ}$. de novembro de 1931, o elogiar aos sócios falecidos particularizava "o trabalho por eles prestados ao Instituto, e destarte a São Paulo e ao Brasil" (IHGSP, 1939a, p.340). Por sua vez, navisão de Eugenio Egas ${ }^{4}$, ao traçar o perfil de nove

4 Foi promotor público, e também vereador e intendente municipal em São Carlos-SP entre 1892-1896, além de deputado estadual (1895-1903) na Assembleia paulista. Atuou ainda

Inf. Inf., Londrina, v. 21, n. 3, p. 5 - 33, set./dez., 2016. 
Carlos Roberto Massao Hayashi, Camila Carneiro Dias Rigolin, Vera Aparecida Lui

Guimarães, Maria Cristina Piumbato Innocentini Hayashi

Colégio invisível, revisão pelos pares e normalização documentária na revista do instituto histórico e geográfico de São Paulo

sócios do IHGSP falecidos no período entre 1916 e 1918, o articulista da RIHGSP deixava claro o papel desses necrológios:

[...] nós aqui estamos para, coligindo e metodizando dados que se achavam esparsos, traçar as linhas principais, que orientem os que desejam celebrar, com pormenores, a memória dos pranteados consócios de que hoje nos lembramos com infinito afeto. Escusado é declarar, portanto, que o meu trabalho, no que diz respeito à coordenação de dados biográficos dos consócios, a que hoje prestamos esta sentida e singela homenagem, limitou-se a reproduzir, com pequeninas alterações, as notícias da imprensa diária, e os apontamentos que pude obter de amigos e parentes dos sócios falecidos. Nem é possível proceder de outra maneira, porquanto o orador do Instituto não conhece a fundo a vida de todos os nossos consócios. Non omnia omnes. De resto, para dispensar certos dados, preciso de tornaria fazer crítica histórica. Não seria então esta a oportunidade para tal estudo; a crítica histórica para ser profunda deve ser feita depois que o tempo tiver, durante dezenas de anos, completado o seu trabalho de extinguir paixões. A nossa reunião é para avivar saudades e depor flores. Sursum corda! (EGAS, 1938, p. 386)

Para além da colaboração dos sócios para publicação de trabalhos na RIHGSP, também eram buscadas contribuições fora do Instituto, conforme sugestão do sócio Duarte Azevedo registrada na Ata da $1^{\text {a }}$ sessãode 25 de janeiro de 1895, do IHGSP:

[...] seria conveniente dirigir-se uma circular às Câmaras Municipais do Estado solicitando a remessa ao Instituto de documentos que existam em seus arquivos que se refiram a pontos da nossa história ou que tenham importância ou interesse geral, porque assim obter-se-iam elementos para o estudo das teses a desenvolver para a organização dos trabalhos, tornando-se também uma fonte de material para a "Revista" publicar (HIGSP, 1895b, p.168).

como redator e secretário do jornal O Estado de São Paulo. Foi casado com a filha de João Carlos de Arruda Botelho, que por sua vez era irmão do tenente-coronel Antonio Carlos de Arruda Botelho, o Conde do Pinhal, um dos fundadores de São Carlos. Faleceu em 1953 com 90 anos de idade.

Inf. Inf., Londrina, v. 21, n. 3, p. 5 - 33, set./dez., 2016. 
Carlos Roberto Massao Hayashi, Camila Carneiro Dias Rigolin, Vera Aparecida Lui Guimarães, Maria Cristina Piumbato Innocentini Hayashi

Colégio invisível, revisão pelos pares e normalização documentária na revista do instituto histórico e geográfico de São Paulo

O processo de submissão de trabalhos a serem publicados na RIHGSP era regulamentado pelo Estatuto do IHGSP, que estipulava, entre outros aspectos, a necessidade de os originais serem enviados ao Presidente que os apresentariam em sessão para a discussão, ou então seriam submetidos a uma Comissão para formulação de um parecer que seria discutido e votado em sessão. Ainda era ressalvado aos sócios o direito de proceder por si mesmos à leitura e apresentação de seus trabalhos em sessão, e quando, por sua extensão ou por qualquer outro motivo, o mesmo não pudesse ser publicado na Revista poderiam fazer inserir em ata um breve resumo desse trabalho (IHGSP, 1939c, p.424). Já no século XX, o Regimento Interno do Instituto disciplinava como seria realizada a revisão de textos a serem publicados na RIHGSP:

\begin{abstract}
Nenhum texto será publicado na Revista do Instituto sem cuidadosa revisão, com vistas à repercussão e oportunidade, facultando-se porém ao autor, no caso de forte restrição, expungí-lo do senão apontado ou alterá-lo pela forma que lhe convier. Parágrafo único - A comissão de redação deverá sempre justificar as restrições feitas, assegurando-se, entretanto, ao autor do trabalho impugnado total ou parcialmente, levar o fato ao conhecimento de assembleia ordinária ou extraordinária, se o desejar, após haver recorrido, sem êxito, em reunião da Diretoria (IHGSP, 1966, p. 348).
\end{abstract}

Ou seja, desde o início, para publicação dos trabalhos a RIHGSP se pautou pela "revisão pelos pares". De acordo com esse processo de avaliação - representado pela norma do ceticismo organizado que compõe o ethos da ciência moderna, e segundo a qual os resultados de pesquisas, ideias e teorias devem ser testados e estão sujeitos ao rigoroso escrutínio da comunidade estruturada (MERTON, 1970, 1977) - é solicitado aos 'pares', que são escolhidos por sua formação e conhecimento a respeito do assunto tratado no texto submetido, a emissão de uma opinião informada e confiável sobre o trabalho original. Configura-se assim, o que Price (1976) chamou de "colégios invisíveis" - que se constituíram desde o século XVII e receberam essa denominação para se diferenciar dos colégios universitários - cuja função era a

Inf. Inf., Londrina, v. 21, n. 3, p. 5 - 33, set./dez., 2016. 
Carlos Roberto Massao Hayashi, Camila Carneiro Dias Rigolin, Vera Aparecida Lui Guimarães, Maria Cristina Piumbato Innocentini Hayashi

Colégio invisível, revisão pelos pares e normalização documentária na revista do instituto histórico e geográfico de São Paulo

de propiciar que grupos de estudiosos trocassem informações sobre suas teorias e descobertas, ainda que não se conhecessem pessoalmente. Essa prática da RIHGSP também acontecia no IHGB, conforme explica Schwarcz (1989, p48), pois nas reuniões dos sócios, "temas previamente esboçados eram debatidos e, conforme fossem aceitos pela comissão de publicações, poderiam ou não figurar entre os artigos da Revista do IHGB".

Assim é que no primeiro fascículo do volume inaugural da RIHGSP estavam explicitados como funcionava o "colégio invisível" no IHGSP, pois informava que "alguns trabalhos foram aprovados em assembleia geral, a fim de serem publicados, e continuará a publicação de outros que já foram lidos [e aprovados nas assembleias]". (IHGSP, 1895a, p. II). O extrato da Ata da 10 . Sessão ocorrida em 5 de agosto de 1895 descrevia com detalhes o processo de "revisão pelos pares":

O sr. dr. Domingos Jaguaribe propõe que seja o seu trabalho Origens republicanas do Brasil submetido à deliberação na presente sessão para o fim de poder ser publicado na Revista, caso seja aprovado visto corno até hoje não foi apresentado o parecer da Comissão a qual foi remetido. É aprovado que o dito trabalho do sr. dr. Jaguaribe seja publicado na Revistado Instituto. O sr. dr. Theodoro Sampaio procede a leitura de um seu trabalho histórico sobre a fundação da primeira colônia regular dos portugueses em São Vicente, finda a qual foi aplaudido e felicitado. $\mathrm{O}$ sr. Presidente consulta a casa se o bem elaborado trabalho que acaba de ser lido deve ou não ser publicado na Revista; a Assembleia, sem debate e por votação unânime, responde afirmativamente (IHGSP, 1895b, p.182)

O mesmo aconteceu na $13^{a}$. Sessão do IHGSP, de 20 de setembro de 1895, quando o sócio Antonio de Toledo Piza pediu a palavra para fazer uma exposição e leitura dos trabalhos apresentados ao Instituto e o plenário "deliberou que tais trabalhos fossem publicados na Revista" (IHGSP, 1895b, p.186). Um deles, a Oração fúnebre, pronunciada pelo Padre Diogo Feijó, em Itu, aos 2 de junho de 1821 já havia sido publicado, mas a explicação para sua aceitação foi a de que este discurso havia sido publicado há muitos anos, em um folheto cuja edição se encontrava esgotada, e a tiragem havia sido

Inf. Inf., Londrina, v. 21, n. 3, p. 5 - 33, set./dez., 2016. 
Carlos Roberto Massao Hayashi, Camila Carneiro Dias Rigolin, Vera Aparecida Lui Guimarães, Maria Cristina Piumbato Innocentini Hayashi

Colégio invisível, revisão pelos pares e normalização documentária na revista do instituto histórico e geográfico de São Paulo

"pequena e distribuída entre amigos do finado" (FEIJÓ, 1896, p.15).

\section{O PROCESSO EDITORIAL DA RIHGSP}

A periodicidade e finalidade da RIHGSP foram fixadas no Estatuto de 1894 do IHGSP - e mantidas nas diversas modificações desse instrumento normativo que ocorreram posteriormente - ao estipular que a Revista seria "publicada periodicamente, todavia, não devendo ser superior a um ano o espaço decorridoentre um e o outro número consecutivos" (IHGSP, 1938a, p. 267).

Contudo, embora prevista em termos estatutários para ser publicada anualmente, em virtude de dificuldades financeiras do IHGSP para a impressão dos exemplares, nem sempre a RIHGSP pode manter essa periodicidade. Muitas vezes um volume englobava vários anos civis - e o contrário também acontecia, ou seja, vários volumes corresponderem ao mesmo ano - o que dificultava a identificação correta de volume e número publicados. Aliado a isso, na folha de rosto da RIHGSPconstava em algarismos romanos o número do volume, mas nem sempre o ano, e ao pé da página constava a data da impressão, que geralmente não correspondia ao ano. Isso se refletiu na organização do volume índice inserido no cd-rom da coleção da Revista. O certo é que de 1895 até 2004 foram publicados 96 volumes. Após um interregno de 10 anos, em julho de 2014 foi lançado o volume 97 da RIHGSP.

Desde o primeiro volume (1895) até a década de 1940, era o próprio Instituto quem financiava a impressão da RIHGSP, embora nem sempre possuísse recursos suficientes para manter a periodicidade anual. Talvez por isso, na sessão de 5 de agosto de 1912, presidida por Eugenio Egas, foi proposta a criação de um fundo de publicações, composto de $50 \%$ da renda do Instituto, o produto das vendas das coleções da Revista e donativos de sócios e pessoas que desejassem auxiliar o "fundo" (IHGSP, 1912, p. 482). A partir de 1950 algumas edições passam a ser subvencionadas pela Câmara Municipal de São Paulo, conforme registrado em rodapé na folha de rosto dos 
Carlos Roberto Massao Hayashi, Camila Carneiro Dias Rigolin, Vera Aparecida Lui Guimarães, Maria Cristina Piumbato Innocentini Hayashi

Colégio invisível, revisão pelos pares e normalização documentária na revista do instituto histórico e geográfico de São Paulo

exemplares da RIHGSP.

$\mathrm{Na}$ apresentação do volume 80 , de 1985, o presidente do IHGSP, Lycurgo de Castro Santos Filho (1985, p. 5) informava que se retomava a publicação da RIHGSP suspensa desde 1984, "em virtude da verdadeiramente brutal elevação dos preços do papel e da mão-de-obra tipográfica" impedindo o Instituto de arcar com as "bastante elevadas despesas de impressão, mesmo reduzindo-se drasticamente a tiragem e a quantidade de páginas". Contudo, graças à lei federal 7.505, de 2 de julho de $1986^{5}$, o numerário requerido para a impressão dos volumes 80 (1985), 82 (1987) e 83 (1988) foi fornecido pela Associação Beneficente "Major Pires de Campos"6, de São Paulo. Isso se repetiu com o volume 81 (1986), que foi patrocinado pelo Dr. José Prudente de Moraes Sampaio. Para a impressão dos volumes 84 e 85 (1989, 1990), Duílio Crispim Farina, que ocupava o cargo de primeiro orador do IHGSP, conseguiu um preço acessível para a edição junto à Editora KMK (SANTOS FILHO, 1989, p. 5). Em 1991, o volume 87 da RIHGSP foi impresso com a colaboração da Imprensa Oficial do Estado. Na apresentação dessa edição, Hernâni Donato, então presidente do Instituto, afirmava sobre a RIHGSP:

A Revista figura entre as tradições mais queridas do nosso Instituto. Ela tem resistido a toda sorte de dificuldades durante os anos em que vem sendo publicada. Ao determinar, estatutariamente que ela deve aparecer ao menos uma vez ao ano, os idealizadores da entidade imaginaram-na como repositório, tribuna e porta-voz. [...] Algumas modificações no seu todo, especialmente quanto ao aspecto gráfico, já se podem notar neste número. Devemo-las, ao propósito impositivo de atualizar a Revista também no seu aspecto material. [...] Este número é bem um retrato do Instituto: por ele se poderá acompanhar as atividades burocráticas e culturais, além de conhecer os trabalhos de sócios, elaborados com finalidade clara de remontar fastos e pessoas e de atividades de outras cidades e associações, com as quais o Instituto colaborou em diversas oportunidades (DONATO, 1992, p.3).

5 Essa Lei dispunha sobre benefícios fiscais na área do imposto de renda concedidos a operações de caráter cultural ou artístico (BRASIL, 1986).

6 Essa Associação foi presidida em 1986 , quando de seu falecimento, por Vinício Stein de Campos, que naquela ocasião também era $1^{\circ}$. Secretário da Diretoria do IHGSP.

Inf. Inf., Londrina, v. 21, n. 3, p. 5 - 33, set./dez., 2016. 
Carlos Roberto Massao Hayashi, Camila Carneiro Dias Rigolin, Vera Aparecida Lui Guimarães, Maria Cristina Piumbato Innocentini Hayashi

Colégio invisível, revisão pelos pares e normalização documentária na revista do instituto histórico e geográfico de São Paulo

As dificuldades para publicação da RIHGSP eram recorrentes, e em 1994 esse assunto voltou à tona, conforme explicava o Editorial da Revista:

O Instituto não ficou imune às dificuldades materiais que afetam a sociedade em geral e, particularmente, as entidades culturais, que sempre contaram com limitados recursos, ora evanescentes. A este percalço, somam-se exigências dos poderes públicos, a sobrecarregar-lhes os encargos, visando, tão somente, majorar a arrecadação. Os critérios burocráticos e fiscais, nestes casos, deslembram-se dos benefícios sociais e culturais que essas Instituições, sem fins lucrativos, espargem, graças ao desprendimento de seus abnegados integrantes. $O$ fenômeno não é exclusividade nosso. Vários países, alguns em estágios mais avançado do que o nosso, padecem do mesmo mal. É um dos sinais dos tempos... . A verdade é que as agruras que essa mentalidade acarreta, afetam não só a divulgação de estudos e pesquisas que contribuem para o engrandecimento moral e intelectual da Nação, mas, igualmente, põe em risco a sobrevivência dessas Entidades, várias delas centenárias e com irrefutável folha de serviços prestados à comunidade (IHGSP, 1994, p. 3).

Em relação aos aspectos da impressão da RIHGSP verificou-se que ela foi impressa em diversas tipografias localizadas na cidade de São Paulo, geralmente de empresas jornalísticas como a Tipografia d'O Município, Tipografia d'El Diário Español, Tipografia do "Diário Oficial" ou "Imprensa Oficial do Estado" - e empresas comerciais, como a Tipografia King, de Carlos Sanches; Tipografia Aurora, Tipografia Andrade, Mello \& Companhia,Gráfica Paulista, de João Bentivegna, a Casa Duprat, a Gráfica Irmãos Canton, Gráfica Sangirardi, Gráfica Bentivegna. KMK Gráfica e Editora, todas localizadas na cidade de São Paulo. Uma exceção foi o volume 16, relativo ao ano de 1911 e publicado em 1914, quefoi impresso na cidade de Tours (França) pela Imprimerie E. Arraultet Cie, graças aos auspícios de Affonso d'Escragnole Taunay.

Em relação à tiragem da $R I H G S P$, a leitura dos Relatórios e Atas publicados na RIHGSP permite inferir que eram impressos um total de exemplares correspondentes ao número de sócios - que tinham o direito de receber a Revista - sendo reservado um quantitativo não especificado para

Inf. Inf., Londrina, v. 21, n. 3, p. 5 - 33, set./dez., 2016. 
Carlos Roberto Massao Hayashi, Camila Carneiro Dias Rigolin, Vera Aparecida Lui Guimarães, Maria Cristina Piumbato Innocentini Hayashi

Colégio invisível, revisão pelos pares e normalização documentária na revista do instituto histórico e geográfico de São Paulo

distribuição para Institutos congêneres e algumas bibliotecas. As edições comemorativas de datas históricas especiais eram impressas em maior tiragem. Por exemplo, a folha de rosto do volume 29, de 1929 - e impresso em 1932 quando foram publicadas as conferências comemorativas do IV Centenário da Fundação de São Vicente (1532-1932) - informava que "deste volume foi feita uma tiragem de 500 exemplares numerados" e que "todos os volumes são rubricados pelo presidente do Instituto", na época, José Torres de Oliveira.

Ou seja, quanto à distribuição da RIHGSP, em todas as atualizações do Estatuto do IHGSP foi mantida a regulamentação de que a Revista seria distribuída gratuitamente aos sócios, e enviada, "a juízo da Diretoria, a autoridades, jornais, bibliotecas e sociedades congêneres"(IHGSP, 1938a, p. 268). Além disso, os sócios em débito não teriam o direito de recebê-la e o preço de venda ao público seria estipulado pela Diretoria.

Por sua vez, em relação às dimensões RIHGSP observou-se que era impressa no formato $16 \times 23 \mathrm{~cm}$, bastante utilizado para livros. O total de páginas variava de acordo com o volume, sendo que os dois primeiros fascículos (volume 1) continham um total de 280 páginas e o último 161páginas. Mas também existiram volumes com mais de 500 e até 1000 páginas.

\section{OS ASPECTOS FORMAIS DA RIHGSP}

O editorial do volume 92, de 1996, informava as modificações introduzidas na RIHGSP partir de então, e que diziam respeito à nova apresentação gráfica e distribuição das matérias em seções, em que se agrupam assuntos na conformidade do tratamento dispensado pelos autores, tais como: EditorialouApresentação e do Noticiário Social (Relatório da Diretoria, Balanços e Prestação de Contas, Atas e Quadro Social), Ensaios, Artigos, Depoimentos e/ou Entrevistas, Conferências e Palestras, Ensaios Bibliográficos, Documentação, Transcrições - podendo incluir matéria 
Carlos Roberto Massao Hayashi, Camila Carneiro Dias Rigolin, Vera Aparecida Lui Guimarães, Maria Cristina Piumbato Innocentini Hayashi

Colégio invisível, revisão pelos pares e normalização documentária na revista do instituto histórico e geográfico de São Paulo

publicada em número anterior da Revista -, Notas e Comentários, Diversos. Além disso, com o propósito de uniformizar o critério a ser seguido pelos colaboradores, e visando atualizar a RIHGSP permitindo-lhe "assegurar o prestígio científico de que gozava" informava-se que a partir do volume 93 entrariam em vigor as seguintes Normas para Publicação:

A Revista destina-se à publicação de trabalhos originais dos sócios e colaboradores convidados sobre História, Geografia e Ciências afins. Os trabalhos apresentados serão submetidos ao exame da Comissão de Redação, que se reserva o direito de recusa. Os originais, redigidos em português, devem ser datilografados em espaço duplo, com margens, contendo um mínimo de 10 (dez) páginas de tamanho ofício, acompanhados das referências bibliográficas, de preferência em notas \& rodapé. Os originais devem ser acompanhados de um resumo com cerca de 50 (cinquenta) palavras, que permitam compreensão global antecipada do tema tratado. É facultado aos autores indicar, concisamente, os títulos que constarão de seus créditos. Os originais serão endereçados à Comissão de Redação e entregues à secretaria administrativa do Instituto. É de exclusiva responsabilidade dos respectivos autores a redação e os conceitos por eles emitidos em seus trabalhos (IHGSP,1996, p. 3).

Quando analisamos a RIHGSP à luz das normas atuais de documentação e informação elaboradas pela ABNT - Associação Brasileira de Normas Técnicas- verificamos que a partir do volume 93, a RIHGSP passou a contar com os elementos estipulados na NBR 6021 - norma brasileira de informação e documentação sobre apresentação de publicação periódica impressa7, ou seja: a) possuir o código 0100-2953 do ISSN8 (International

\footnotetext{
7 As normas aplicadas à produção bibliográfica acadêmica fazem parte do escopo do CB14 Comitê Brasileiro de Documentação e Informação da ABNT que se reúne regularmente para as atualizações necessárias. A primeira versão da norma 6021 é de 1994 e a atual, de 2003.

8 Sigla em inglês para Número Internacional Normalizado para Publicações Seriadas. De acordo com Santos (2011, p.9) "é atribuído desde a década de 1970 e universalmente aceito na edição impressa como meio de identificar as publicações seriada". Seu uso não é obrigatório, mas confere vantagens ao editor uma vez que ele possibilita rapidez, produtividade, qualidade e precisão na identificação e controle da publicação seriada nas etapas da cadeia produtiva editorial (IBICT, 2014).
}

Inf. Inf., Londrina, v. 21, n. 3, p. 5 - 33, set./dez., 2016. 
Carlos Roberto Massao Hayashi, Camila Carneiro Dias Rigolin, Vera Aparecida Lui Guimarães, Maria Cristina Piumbato Innocentini Hayashi

Colégio invisível, revisão pelos pares e normalização documentária na revista do instituto histórico e geográfico de São Paulo

Standard Serial Number); b) apresenta rlegenda bibliográfica; e c) inserção de ficha catalográfica no verso da folha de rosto. O conteúdo e a localização sequencial desses elementos, contudo, se apresentaram em desacordo ${ }^{9} \mathrm{com}$ o estipulado na norma.

$\mathrm{Na}$ visão de Hayashi et al. (2006) o uso de normas e padrões é importante para o reconhecimento e a eficácia dos periódicos científicos como disseminador do conhecimento. Contudo, conforme relatado por Crespo e Rodrigues (2011) a normalização em várias áreas de conhecimento já existia em outros países desde o início do século XX, mas no Brasil somente a partir de 1940, com a criação da ABNT é que essas normas começaram a ser aplicadas.

A despeito dos propósitos fixados em 1996 quanto à normalização documentária da RIHGSP, os artigos publicados no volume seguinte, em 1997, não estavam de acordo com as normas adotadas. A justificativa da Comissão de Redação foi a de que vários originais entregues anteriormente à adoção daquelas regras acumulavam-se no Instituto, e a "importância desse material e o conceito de seus autores impunha o aproveitamento" (IHGSP, 1997, p. 5).

A RIHGSP também publicava um "Índice Repertório", e no período entre 1895 a 1989 foram elaboradas três edições com esse conteúdo. Da perspectiva biblioteconômica, e de acordo com a NBR-6034 da ABNT, que estabelece os requisitos e critérios básicos para a apresentação de um índice, esse é definido como "uma relação de palavras ou frases, ordenadas segundo determinado critério, que localiza e remete para as informações contidas em um texto". Em relação ao conteúdo, um índice deve relacionar informações extraídas do documento no todo desde a introdução até os anexos, incluindo as ilustrações. As entradas podem ser complementadas com informações não contidas no documento, como nomes completos, pseudônimos, datas etc. $\mathrm{O}$

\footnotetext{
9 Por exemplo, o ISSN na ficha catalográfica está grafado como "ISSM"; a legenda bibliográfica só aparece na folha de rosto e a apresentação dos elementos pré-textuais não seguem a ordem preconizada na NBR 6021.
}

Inf. Inf., Londrina, v. 21, n. 3, p. 5 - 33, set./dez., 2016. 
Carlos Roberto Massao Hayashi, Camila Carneiro Dias Rigolin, Vera Aparecida Lui Guimarães, Maria Cristina Piumbato Innocentini Hayashi

Colégio invisível, revisão pelos pares e normalização documentária na revista do instituto histórico e geográfico de São Paulo

índice pode ser classificado em dois tipos: especial: quando contém entradas específicas separadas por um tipo de informação - por exemplo, índice onomástico, de nomes de personagens, de autoridades citadas ao longo de umrelatório, de assuntos, entidades, nomes geográficos, títulos, citações, anunciantes e matérias publicitárias; e geral, quando combina duas ou mais características indicadas anteriormente, por exemplo: índice de autores e de assuntos. Portanto, o que na RIHGSP denominaram de "índice-repertório" enquadrava-se na categoria de índice geral.

O primeiro índice-repertório, publicado em 1938 e em um volume denominado $30-B i s$ (exclusivo para isso) e abrangia os 30 primeiros volumes. Foi organizado por Dacio Pires Correia, que na página de abertura da RIHGSPexplicava os motivos para a organização dessa publicação:

A magnífica coleção da Revista do Instituto Histórico e Geográfico de São Paulo guarda em suas páginas contribuições valiosas firmadas por nomes consagrados nas diversas províncias da intelectualidade patrícia. Ela nos mostra exuberantemente a atividade esplêndida de um período superior a 40 anos da patriótica associação piratiningana, entidade que vem com um carinho admirável zelando das tradições imperecíveis da gente bandeirante. Mas, à excelente publicação faltava, entretanto, um índice, esse instrumento precioso para quem moureja no campo exaustivo da investigação. Por essa razão muitos estudiosos têm o seu fichário de conformidade, porém, com a sua especialização ou predileção de matéria, motivo, sem dúvida, de não terem divulgado essas observações colhidas no exame paciente de 15.000 páginas de assuntos tão variados. Decorre desse fato que nosso Índice-Repertório, imperfeito, naturalmente, pelas dificuldades de quem desconhece os segredos da biblioteconomia, dificuldades que procuramos remover com a boa vontade que nunca nos faltou neste empreendimento que visa facilitar o comércio com tantas produções de valia, notadamente no campo da História e da Geografia pátrias. [...] Ao sr. Dr. Paulo Duarte os nossos melhores agradecimentos pelo auxílio dado com a oferta do seu fichário particular, que veio suavizar bastante a elaboração do projetado indicador", despretensiosa colaboração que, com certo júbilo, apresentamos aos dignos pesquisadores dos feitos de nossos avoengos (IHGSP, 1938c, p. 3, grifo nosso).

Inf. Inf., Londrina, v. 21, n. 3, p. 5 - 33, set./dez., 2016.

http:www.uel.br/revistas/informacao/ 
Carlos Roberto Massao Hayashi, Camila Carneiro Dias Rigolin, Vera Aparecida Lui Guimarães, Maria Cristina Piumbato Innocentini Hayashi

Colégio invisível, revisão pelos pares e normalização documentária na revista do instituto histórico e geográfico de São Paulo

O volume 60, publicado em 1964 trouxe o segundo índice, denominado de "Índice Alfabético" cobrindo os volumes 1 a 59 da RIHGSP. Ressalva era feita ao fato de que o índice relativo aos volumes 1 a 30 , e da lavra de Dacio Pires Correia já houvera sido publicado anteriormente, mas o próprio autor considerou-o "demasiado falho" e se propôs a organizar um novo índice alcançando até o volume 51 , ocasião em que "reviu e refez de maneira eficiente o trabalho primitivo, de modo a poder ser republicado" (LEITE, 1964, p.5). Só não completou essa tarefa tendo em vista o seu falecimento, o que foi realizado pelo sócio Salvador Rocco, responsável pelo índice dos volumes 52 a $59^{10} \mathrm{O}$ presidente do IHGSP complementava a apresentação sobre o índice ressalvando que:

Dada, porém, a carência do tempo diante a necessidade de se entregarem logo os originais às oficinas gráficas da Indústria Gráfica Bentivegna Ed. Ltda., que se tem mostrado tão amiga do Sodalício, o índice, em apêndice, dos volumes por último aludido, pecam o seu tanto na minuciosidade desejável. Mas, assim mesmo, tornaram-se úteis à sua consulta. Daqui a trinta anos, mais ou menos, quando for preciso um novo índice para os novos volumes da REVISTA, há de surgir novo Dacio que, com mais tempo e armado de sua capacidade, amor ao Instituto e pertinácia, se incumba de organizá-lo como se deve e, por certo, da revisão e refatura dos índices acrescidos agora em apêndice (LEITE, 1964, p.4).

Por sua vez, no volume 89 da RIHGSP, referente ao ano 1994 foi publicado o Índice dos volumes 51 a 88 e elaborado pelos sócios Délio Freire dos Santos, Roberto Machado de Carvalho e Walter Pinheiro Guerra, assistidos pela Comissão de Redação da RIHGSP. De acordo com Hernâni Donato, Presidente do IHGSP, "as solicitações reiteradas para que esse índice fosse realizado" era um "indicador do apreço em que a revista é tida, assim em

10 Contudo, ao consultarmos o volume 60, verificamos que a complementação de Salvador Rocco abrangeu apenas os volumes 51 a 54, conforme o "Adendo ao índice geral correspondente aos volumes 51 a 54" (IHGSP, 1964, p.521-535).

Inf. Inf., Londrina, v. 21, n. 3, p. 5 - 33, set./dez., 2016. 
Carlos Roberto Massao Hayashi, Camila Carneiro Dias Rigolin, Vera Aparecida Lui Guimarães, Maria Cristina Piumbato Innocentini Hayashi

Colégio invisível, revisão pelos pares e normalização documentária na revista do instituto histórico e geográfico de São Paulo

São Paulo como no País e mesmo no exterior" (DONATO, 1994, p. 2).

Ainda em relação à publicação de "Índices" foram publicados,em 1967,nos volumes 63 e 64 da RIHGSP, dois semestres das "Efemérides Paulistas".Conforme explicava o presidente do IGHSP:

[...] as efemérides de uma nação, de organismo regional, que a integra, estado, distrito, ou cidade, seriadas por dias, meses e anos, apresentam dupla feição de interesse e de aproveitamento. Servem a todos como índice ou roteiro da história. Doutra parte, àqueles que, sem terem no trato dos fastos a continuidade perquiridora do historiador, procuram esclarecimentos esporádicos, oferecem um vasto repositório de precisos informes, alinhados por suas respectivas datas (LEITE, 1967, p. 3).

O pretexto dessa publicação surgiu da prática de leitura, no início dassessões plenárias do Instituto, das "Efemérides Brasileiras" de autoria do Barão do Rio Branco e das Paulistas que foram compiladas por uma comissão de consócios integrada pelo Cel. Arrison de Souza Ferraz e Drs. Alfredo Gomes e Mario Leite - e ampliada com a participação dos Drs. Célio Debes, Jacob Penteado e do Cel. Benito Serpa - que aceitaram a incumbência de completar essas efemérides para todos os dias do ano e não apenas para as sessões plenárias. O trabalho da comissão "se apoiou em vasta matéria existente, nela coligindo referências a acontecimentos paulistas de relevo, como é óbvio, até à época das publicações consultadas", e complementadas com efemérides mais recentes (LEITE, 1967, p. 3).

O sentido das "Efemérides Paulistas", conforme declarado na apresentação do volume 63 , era o de "culto das histórias pátrias e paulistas", reforçando mais uma vez a frase emblemática que abriu o primeiro volume da RIHGSP: "A história de São Paulo é a própria história do Brasil" (IHGSP, 1895a, p. 1, grifo nosso), ou seja, fortaleci aos propósitos do IHGSP de reescrever a história nacional com base nos exemplos paulistas. Como refere Schwarcz (2004, p.165), o IGHSP ao "falar da particularidade" também mostrava como "a história paulistana representava um "cadinho" da história 
Carlos Roberto Massao Hayashi, Camila Carneiro Dias Rigolin, Vera Aparecida Lui Guimarães, Maria Cristina Piumbato Innocentini Hayashi

Colégio invisível, revisão pelos pares e normalização documentária na revista do instituto histórico e geográfico de São Paulo

nacional". Essa visão se consubstanciava na elaboração das "efemérides paulistas", para justificar aquilo quee Aureliano Leite chamava de "nobre passado de São Vicente e de São Paulo" ao argumentar que

[...] por seu entrosamento com o de outras regiões do País, teria provocado a asserção que está nos anais da Província de São Paulo, do Visconde de São Leopoldo, de que "A história da capitania de São Vicente será a história geral do Brasil". Os que, por ventura considerarem que só o entusiasmo do ilustre santista o tenha induzido a esse conceito, que se voltem atentamente para a tradição de São Paulo - capitania, província, estado - para aí verificarem como a história paulista se reflete em quase toda a história do Brasil. (LEITE, 1967, p. 3 , grifo nosso).

Contudo, uma autocrítica sobre o trabalho realizado foi feita na apresentação do volume 64 que continha o segundo semestre das "Efemérides Paulistas". Alegava o presidente do IHGSP que, "a despeito dos esforços meritórios de seus ilustres compiladores" o volume "não saiu com a perfeição desejada" haja vista que "a redação dos verbetes não obedeceu a critério único" e que "a adjetivação tornou-se, por vezes, exagerada" (LEITE, 1967, p. 3). Para a elaboração do segundo volume os compiladores se valeram da mesma bibliografia consultada acrescida de outrasfontes, como o Catálogo de Documentos do Arquivo Ultramarino de Lisboa, além de também trazer um índice de pessoas e assuntos.

\section{EM MODO DE CONCLUSÃO}

Tendo fixado como um dos seus objetivos manter correspondência e relações com as sociedades congêneres, nacionais e estrangeiras, além de publicar textos científicos e literários, nas páginas da RIHGSP pode ser observada a intensa atividade de comunicação científica entre os membros do IHGSP.As Atas das Seções transcritas ao final de cada edição da revista também oferecem importantes subsídios para o estudo dos diversos aspectos do processo de comunicação científica.

Inf. Inf., Londrina, v. 21, n. 3, p. 5 - 33, set./dez., 2016. 
Carlos Roberto Massao Hayashi, Camila Carneiro Dias Rigolin, Vera Aparecida Lui Guimarães, Maria Cristina Piumbato Innocentini Hayashi

Colégio invisível, revisão pelos pares e normalização documentária na revista do instituto histórico e geográfico de São Paulo

O estudo realizado permitiu compreender como ocorria a revisão pelos pares no IHGSP, o funcionamento do colégio invisível e o processo editorial e de normalização documentária da RIHGSP.Os resultados obtidos lançam luzes para futuras investigações sobrea comunicação científica em revistas congêneres, em busca de suas similaridades ou diferenças, pois como já referiu Ziman (1981)os periódicos nos contam muita coisa sobre a comunidade cientifica e o modo como ela trabalha.

\section{REFERÊNCIAS}

ABNT - ASSOCIAÇÃO BRASILEIRA DE NORMAS TÉCNICAS.NBR 6021: informação e documentação: publicação periódica científica impressa apresentação. Rio de Janeiro, maio 2003.

Janeiro, dez. 2004.

NBR 6034: informação e documentação: índice - apresentação. Rio de

BRASIL. Lei $n^{\circ} 7505$, de 2 de julho de 1986. Dispõe sobre benefícios fiscais na área do imposto de renda concedidos a operações de caráter cultural ou artístico. Disponível em: <http://www.planalto.gov.br/ccivil_03/leis/L7505.htm>. Acesso em: 30 jun. 2014.

CALLARI, Cláudia Regina. Os institutos históricos: do patronato de D. Pedro II à construção do Tiradentes. Revista Brasileira de História, São Paulo, v. 21, n. 40 , p. 59-83. 2001.

CRESPO, Isabel Merlo; RODRIGUES, Ana Vieira Finardi. Normas técnicas e comunicação científica: enfoque no meio acadêmico. Revista Digital de Biblioteconomia e Ciência da Informação, Campinas, v. 9, n. 1, p. 3655,jul./dez. 2011.

DONATO, H. Apresentação. Revista do IHGSP, São Paulo, v. 87, p. 3, 1992. . Apresentação. Revista do IHGSP, São Paulo, v. 89, p. 2, 1994.

EGAS, Egas. Elogios históricos (1916-1918). Revista do Instituto Histórico e Geográfico de São Paulo, São Paulo, v. 34, p. 341-432, 1938.

FEIJÓ, Antonio Diogo, Padre.Oração fúnebre. Revista do IHGSP, São Paulo, v. 1, n. 2, p.15-26. 1896.

Inf. Inf., Londrina, v. 21, n. 3, p. 5-33, set./dez., 2016. 
Carlos Roberto Massao Hayashi, Camila Carneiro Dias Rigolin, Vera Aparecida Lui Guimarães, Maria Cristina Piumbato Innocentini Hayashi

Colégio invisível, revisão pelos pares e normalização documentária na revista do instituto histórico e geográfico de São Paulo

FERREIRA, Antonio Celso. A epopeia bandeirante: letrados, instituições, invenção histórica (1870-1940). São Paulo: EDUNESP, 2002.

. Entre a tradição e a modernidade, entre a História e o romance:

IHGSP 100 anos. Revista do Instituto Histórico e Geográfico de São Paulo, São Paulo, v. 90, p.14-26, 1995.

FERREIRA, Antonio Celso; MAHL, Marcelo Lapuente. Preservação e patrimônio no Instituto Histórico e Geográfico de São Paulo (1894-1937).

Patrimônio e Memória, Assis, v. 7, n. 1, p. 3-18, jun. 2011.

GUIMARÃES, M. S. Nação e civilização nos trópicos: o Instituto Histórico e Geográfico Brasileiro. Revista Estudos Históricos, Rio de Janeiro, v. 1, n. 1, p. 5-27, jan. 1988.

GUIMARÃES, Lúcia Maria Paschoal. Da Escola Palatina ao Silogeu: Instituto Histórico e Geográfico Brasileiro (1889-1938). Rio de Janeiro: Museu da República, 2007.

. Debaixo da imediata proteção de Sua Majestade Imperial: o Instituto Histórico e Geográfico Brasileiro (1838-1889). Revista do Instituto Histórico e Geográfico Brasileiro, Rio de Janeiro, v. 156, n. 388, p. 459-613,jul./set. 1995.

HAYASHI, Maria Cristina Piumbatolnnocentini et al. Avaliação de aspectos formais em quatro periódicos científicos na área de educação especial. Revista Brasileira de Educação Especial, Marília, v. 12, p. 369-392, 2006.

IBICT. Sobre o ISSN. 2014. Disponível em: <http://www.ibict.br/informacaopara-ciencia-tecnologia-e-inovacao\%20/centro-brasileiro-do-issn>. Acesso em: 30 jun. 2014.

IHGSP - INSTITUTO HISTÓRICO E GEOGRÁFICO DE SÃO PAULO. Adendo ao índice geral correspondente aos volumes 51 a 54. Revista do IHGSP, São Paulo, v. 60, p. 521-535, 1964.

Ao Leitor. Revista do IHGSP, São Paulo, v. 1, n. 1, p. I-II, 1895a.

. Ata da Assembleia Geral do IHGSP, realizada no dia 13 de outubro de 2004, para a eleição da diretoria para o triênio 2005-2008. Revista do IHGSP, São Paulo, v. 96, p. 159-161, 2004a.

. Ata da sessão de 16 de fevereiro de 1963. Revista do IHGSP, v.62, p. 343-359, 1966. 
Carlos Roberto Massao Hayashi, Camila Carneiro Dias Rigolin, Vera Aparecida Lui Guimarães, Maria Cristina Piumbato Innocentini Hayashi

Colégio invisível, revisão pelos pares e normalização documentária na revista do instituto histórico e geográfico de São Paulo

IHGSP - INSTITUTO HISTÓRICO E GEOGRÁFICO DE SÃO PAULO. Atas das sessões do ano de 1901. Revista do IHGSP, São Paulo, v. 6, p. 592-623, 1900-1901. $186,1895 \mathrm{~b}$.

Atas das sessões. Revista do IHGSP, São Paulo, v. 1, n. 1, p. 159-

Atas das sessões de 1912. Revista do IHGSP, São Paulo, v. 17, p. 469-492, 1912.

. Atas de janeiro de 1931 a novembro de 1933. Revista do IHGSP, São Paulo,v. 36, p. 313-402, 1939a.

. Atas de janeiro a junho de 1939. Revista do IHGSP, São Paulo, v. 36, p. 403-414, 1939b.

. Diretoria do triênio 2002-2004 e 2005-2007. Revista do IHGSP, São Paulo, v. 96, 2004b.

. Editorial. Revista do IHGSP, São Paulo,v. 92, 1996.

. Editorial. Revista do IHGSP, São Paulo, v. 93, 1997.

. Editorial. Revista do IHGSP, São Paulo, v. 94, 1994.

. Estatuto e Regimento Interno do Instituto Histórico e Geográfico de São Paulo aprovado nas sessões de 20 de outubro de 1936 e 10 de janeiro de 1937, respectivamente. Revista do IHGSP, São Paulo, v. 32, p. 427-445, 1937.

. Estatutos. Revista do IHGSP, São Paulo, v. 36, p. 259-273, 1938a.

- Noticiário social: atas das sessões do ano de 1996. Revista do IHGSP, São Paulo, v. 95, p. 195-226,1999.

Novos estatutos aprovados na sessão regimental de 20 de maio de 1932. Revista do IHGSP, São Paulo, v. 31, p. 465-482, 1933-1934.

Disponível em:

Presidentes do Instituto Histórico e Geográfico de São Paulo.

<http://www.ihgsp.org.br/abl/cgi/cgilua.exe/sys/presidentes.php?sid=10>. Acesso em: 30 set. 2015.

Revista do IHGSP, São Paulo, v. 34, p. 341-434, 1938 b.

. Revista do IHGSP, São Paulo, v. 30-Bis, p .3, 1938c.

Inf. Inf., Londrina, v. 21, n. 3, p. 5 - 33, set./dez., 2016.

http:www.uel.br/revistas/informacao/ 
Carlos Roberto Massao Hayashi, Camila Carneiro Dias Rigolin, Vera Aparecida Lui Guimarães, Maria Cristina Piumbato Innocentini Hayashi

Colégio invisível, revisão pelos pares e normalização documentária na revista do instituto histórico e geográfico de São Paulo

. Velhos estatutos (1894 e 1901). Revista do IHGSP, São Paulo, v. 36, p. 415-449. 1939c.

LEITE, A. Apresentação. Revista do IHGSP, v.60, p.5-6, 1964.

. Apresentação. Revista do IHGSP, v.63, p. 3-4, 1967.

MERTON, Robert King. La Sociología de laciencia. Madrid: Alianza Editorial, 1977.

Sociologia: teoria e estrutura. São Paulo: Mestre Jou, 1970.

PEREIRA, Maria Aparecida; FERREIRA JUNIOR, Amarílio; HAYASHI, Maria Cristina Piumbatolnnocentini. Os Institutos Históricos e Geográficos no Brasil: estudo bibliométrico do banco de teses da CAPES. In: HAYASHI, Maria CrisitinaPiumbatolnnocentini; FARIA, Leandro Innocentini Lopes; HAYASHI, Carlos Roberto Massao (Org.) Bibliometria e cientometria: estudos temáticos. São Carlos: Pedro \& João, 2013, p. 229-246.

PRICE, Derek J. de Solla. O desenvolvimento da ciência: análise histórica, filosófica, sociológica e econômica. Rio de Janeiro: LTC, 1976.

SANTOS FILHO, L. de C. Apresentação. Revista do IHGSP, São Paulo,v. 80, p. $5,1985$.

. Apresentação. Revista do IHGSP, São Paulo,v. 84, p. 5, 1989.

SANTOS, Gildenir Carolino. Fontes de indexação para periódicos científicos: um guia para bibliotecários e editores. Campinas: E-Color, 2011.

SCABIN, Rafael Cesar. A discussão sobre João Ramalho no IHGSP: construção da memória e leitura documental. In: SIMPÓSIO NACIONAL DE HISTÓRIA-ANPUH, 26., 2011, São Paulo. Anais... São Paulo: ANPUH, 2011, p. 1-11.

SCHWARCZ, Lilia K. Moritz. Os Guardiões da história oficial> São Paulo: Idesp, 1989.

SCHWARCZ, Lilia K. Moritz. Os institutos históricos e geográficos: "Guardiões da história oficial". In: O espetáculo das raças: cientistas, instituições e questão racial no Brasil (1870-1930) São Paulo: Cia das Letras, 1993, p. 129184.

A construção de uma identidade paulista. In: BUENO, E. Os nascimentos de São Paulo. Rio de Janeiro: Ediouro, 2004. p.163-189.

WEHLING, Arno. De formigas, aranhas e abelhas: reflexões sobre o IHGB. Rio de Janeiro: IHGB, 2010. 
Carlos Roberto Massao Hayashi, Camila Carneiro Dias Rigolin, Vera Aparecida Lui Guimarães, Maria Cristina Piumbato Innocentini Hayashi

Colégio invisível, revisão pelos pares e normalização documentária na revista do instituto histórico e geográfico de São Paulo

. Unidade, diversidade e sociabilidade: o IHGB nos seus 170 anos.

Acervo, Rio de Janeiro, v. 22, n. 1, p. 201-208. jan./jun. 2009.

ZIMAN, John M. A força do conhecimento: a dimensão científica da sociedade. São Paulo: Edusp, 1981.

\title{
Title
}

The invisible college, the peer review and the documentary standardization in the revista do Instituto Histórico e Geográfico de São Paulo

\begin{abstract}
Introduction: The article discusses the peer review the functioning of the invisible college, the editorial process (printing, drawing, timing, distribution) and documentary standardization of a journal that has 121 years of existence: the Journal of Historical and Geographical Institute of São Paulo (RIHGSP).

Objective: this text analyze aspects of scientific communication, publishing and documentary standardization of RIHGSP.

Methodology: Anchored in the theoretical perspective of Information Science and Sociology of Science, the analyzed corpus consisted of 33 articles published in RIHGSP between 1895 and 2004.

Results: The study provides insight into how publishers and authors - who were part of the São Paulo and Brazilian intelligentsia - and published their articles in RIHGSP were part of an invisible college in the field of historical studies.

Conclusions: The results can illuminate future studies of congeners journals in search of similarities or differences with regard to these aspects.
\end{abstract}

Keywords: Revista do Instituto Histórico e Geográfico de São Paulo. Invisible college.Peer review.Scientific communication.

\section{Titulo}

Colegioinvisible, revisión por los pares y normalizaciónenla revista do Instituto Histórico e Geográfico de São Paulo

\section{Resumen}

Introducción: El artículo aborda la revisión por pares, el funcionamiento del colegio invisible, el proceso editorial (impresión, número de copias, periodicidad, distribución) y la normalización documental de una revista que tiene 121 años de existencia: la Revista de Instituto Histórico y Geográfico de Sao Paulo (RIHGSP).

Objetivo: En este artículo se analizan aspectos de la comunicación científica, publicación y normalización documental de RIHGSP.

Metodología: Anclado en la perspectiva teórica de Ciencias de la Información y la sociología de la ciencia, el corpus analizado consistió en 33 artículos publicados en RIHGSP entre 1895 y 2004.

Resultados: El estudio da una idea de cómo los editores y autores - que formaban

Inf. Inf., Londrina, v. 21, n. 3, p. 5 - 33, set./dez., 2016. 
Carlos Roberto Massao Hayashi, Camila Carneiro Dias Rigolin, Vera Aparecida Lui Guimarães, Maria Cristina Piumbato Innocentini Hayashi

Colégio invisível, revisão pelos pares e normalização documentária na revista do instituto histórico e geográfico de São Paulo

parte de la inteligencia brasileña - y publicó su artículos en RIHGSP integran parte de un colegio invisible en el campo de los estudios históricos.

Conclusiones: Los resultados pueden iluminar los estudios futuros de los congéneres de revistas en busca de similitudes o diferencias con respecto a estos aspectos.

Palabras clave: Revista do Instituto Histórico e Geográfico de São Paulo. Colegio invisible. Revisión por pares. Comunicación científica.

Recebido em: 10.04.2016

Aceito em: 18.11.2016

Inf. Inf., Londrina, v. 21, n. 3, p. 5 - 33, set./dez., 2016.

http:www.uel.br/revistas/informacao/ 